ribonucleotides 5'-GCGAAAAATGTGAT$3^{\prime}$ and 5'-CTAGATCACAIIIITCG-3' [underlining denotes differences from Ref. 3]), crystals were grown, and data were collected ${ }^{3}$. Initial phasing models were derived from the structure of the CAP-DNA complex at $2.5 \AA$ \& resolution ${ }^{3}$, modelling Glu 181 and Phe 181 as glycine residues and DNA with the sequence of DNA ${ }_{\text {ICAP. }}$. Initial $R$-factors for CAP-DNA ICAP and [Phe 181]CAPDNA ${ }_{1 C A P}$ were, respectively, $31.5 \%$ for data to $3.5 \AA$ and $33.2 \%$ for data to 3.7 $\AA$. Models were refined by X-PLOR positional refinement ${ }^{26}$, using improved DNA geometrical restraints 3,27 , incorporating water molecules as described $^{3}$ (conservatively for [Phe
181]CAP-DNA ICAP), and incorporating the side chains of Glu 181 and Phe 181 based on unambiguous fits to electron density at $2.9 \AA$ resolution in $2 \boldsymbol{F}_{\mathrm{o}}-\boldsymbol{F}_{\mathrm{c}}$ and $\boldsymbol{F}_{0}-\boldsymbol{F}_{\mathrm{c}}$ maps. Atomic coordinates and structure factors have been deposited in the Brookhaven Protein Data Bank (accession numbers 1RUN, 1RUO).

Gary Parkinson', Angelo

Gunasekera1,3, Jaroslav

Vojtechovsky', Xiaoping

Zhang ${ }^{1,4}$, Thomas A. Kunkel2,

Helen Berman' and Richard $\mathrm{H}$.

Ebright ${ }^{1}$

DDepartment of Chemistry and Waksman
Institute, Rutgers University, New Brunswick, New Jersey 08855, USA 2NIH-NIEHS, Research Triangle Park, North Carolina 27709, USA

3Present address: Abbott Laboratories, Abbott Park, Illinois 60064, USA

4 Present address: Division of Infectious Disease, New England Medical Center, Boston, Massachusetts 02111, USA

Correspondence should be addressed to H.B. and R.H.E.

berman@adenine.rutgers.edu ebright@mbcl.rutgers.edu

Received 19 June; accepted 19 August, 1996.
Acknowledgements We thank M. Smith for preparation of mutants, Y. Ebright for preparation of oligodeoxyribonucieot ides and the Cornell High Energy Synchrotron Source and the Pittsburgh Computer Center for access to facilities. This work was supported by grants from the National Institutes of Health to H.B. and to R.H.E.
1. Kolb, A., Busby, S., Buc, H. Garges, 5. \& Adhya, S. Ann. Rev, Biochem. 62, 749-795 (1993)

2. Schultz, S., Shields, G. \& Steitz, T. Science 253, 1001-1007 (1991)

3. Parkinson, G. et al. J. Mol. Biol. 260, 395-408 (1996).

4. Ebright, R., Cossart, P., Gicquel-Sanzey, B. \& Beckwith, J. Nature 311, 232-235 (1984).

5. Ebright, R., Cossart, P., Gicquel-Sanzey, B. \& Beckwith, J. Proc. Natl. Acad. Sci. USA 81, 7274-7278 (1984).

6. Ebright, R. et al. Proc. Natl. Acad. Sci. USA 84, 6083-6087 (1987).

7. Ebright, R. Meths. Enzymol. 208, 620-640 (1991).

8. Berg, O. \& von Hippel, P. J. Mol. Biol. 200, 709-723 (1988).

9. Ebright, R., Ebright, Y. \& Gunasekera, A. Nud. Acids Res. 17, 10295-10305 (1989).
10. Gunasekera, A., Ebright, Y. \& Ebright, R. J. Biol. Chem. 267, 14713-14720 (1992).

11. Burley S \& Petsko G. FEBS Letts. 203 139-143 (1986)

12. Burley, S. \& Petsko, G. Adv. Protein Chem. 39 125-189 (1988).

13. Levitt, M. \& Perutz, M. J. Mol. Biol. 201 $751-754$ (1988)

14. Perutz, M. in The Chemical Bond (ed Zewail E.) 17-30 (Academic Press, New York, 1992).

15. Jorgensen, W. \& Severance, D. J.Amer. Chem. Soc. 112, 4768-4774 (1990).

6. Suzuki, S. et al. Science 257, $942-945$ (1992).

17. Rodham, D. et al. Nature 362, 735-737 (1993).

18. Atwood, J., Hamada, F., Robinson, K., Orr GW. \& Vincent, R. Nature 349,683-684 (1991).

19. Bakshi, P. et al. Can. J. Chem. 72, 1273-1293 (1993).
20. Warshel, A. \& Levitt, M. J. Mol. Biol. 103 , 227-249 (1976).

21. Mitchell, J., Nandi, C.L., MCDonald, I. \& Thornton, J. J. Mol. Biol. 239, 315-331 (1994).

22. Jamison, R., Kakkad, B., Ebert, D., Newcomer M. \& Ong, D. Biochem. 34, 11128-11132 (1995).

23. Zhang, X., Gunasekera, A., Ebright, Y. \& Ebright, R. J. Biomol. Struct. Dyn. 9, 463-473 (1991).

24. Kunkel, T., Bebenek, K. \& McClary, J. Meths. Enzymol. 204, 125-138(1991).

25. Zhang, X. \& Ebright, R. Proc. Natl. Acad. Sci. USA 87, 4717-4721 (1990).

26. Brünger, A. X-PLOR Manual, Version 3.1 (Yale University Press, New Haven, 1992).

27. Parkinson, G., Vojtechovsky, J., Clowney, L., Brünger, A. \& Berman, H. Acta Cryst. D52, 57-64 (1996).

28. Kraulis, P. J. Appl. Cryst. 24, 946-950 (1991).

picture story

\title{
Phosphorylation turns it on
}

The ubiquity of phosphorylation betrays its importance. Regulation of protein function by phosphorylation is so common, particularly in the propagation of cellular signalling cascades, that no one is now surprised when a new example of such regulation arises. Despite the familiarity that breeds this lack of respect, little is yet
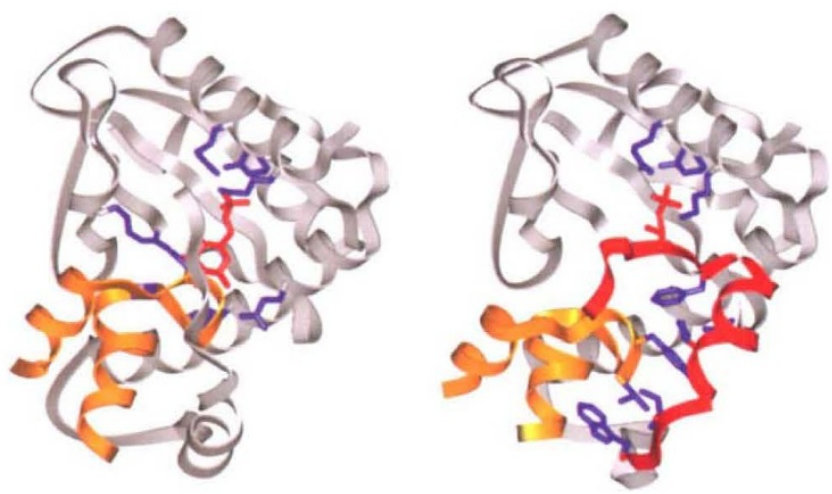

known about the structural features that could explain the mechanism(s) of regulation by phosphorylation, renewing an air of mystery, and hence, attraction.

The structure of the active form of yeast glycogen phosphorylase (GP) - which participates in the conversion of glycogen into glucose-1-phosphate-provides a mechanistic account of the consequences of phosphorylation (K. Lin, V.L. Rath, S.C.Dai, R.J. Fletterick and P.K. Hwang, Science, in the press). A view of the dimer interface of the inactive (left) and active (right) enzymes illustrates the changes on phosphorylation. A portion of one subunit is shown in grey; the 'CAP'loop from the other subunit is in gold. Phosphorylation of a threonine residue (red stick on right) causes a rearrangement of the $\mathrm{N}$ terminus (red ribbons), ultimately effecting a slight separation of the dimers, and exposure of the active sight. The new arrangement of the $\mathrm{N}$ terminus is stabilized by clustering of hydrophobic side chains from the CAP loop and $\mathrm{N}$ terminus (in blue on right). The phosphorylated Thr is coordinated by two Arg residues. The location of an inhibitor (glucose-6-phosphate, on left in red stick) in the allosteric effector site indicates that the inhibitor may work by displacing the phosphorylated Thr side-chain from its active location, exposing the enzyme to inactivation by dephosphorylation. 